8 Lilienfield, L. S., Freis, B. D., Partengpe, B. A., and Morowitz, H. J., 1 .

8 Chinard, F. P., Advances in Respiratory Physio logy, ed. C.. G. Caro, ch. 4. London, Bdwari

\section{Gastric Ulcer after Highly Selective Vagotomy}

SIR,-Because of recurrent episodes of epigastric pain a 34-year-old building laboure had lost seven jobs in seven years and had worked for only two weeks in the seven months before undergoing highly selective vagotomy on 5 July 1971. Stippling of the anterior wall of the first part of the duodenum together with minimal thickening of the lesser curve side of the pylorus were the only abnormalities noted. At this operation $5.5 \mathrm{~cm}$ measured on the lesser curve side of the antrum were left innervated and the oesophagus was thoroughly bared for $6 \mathrm{~cm}$ When his chest was cleared he did well, so that within six weeks he was pain-free and eating larger meals than for years. He did, however, admit to foul eructations.

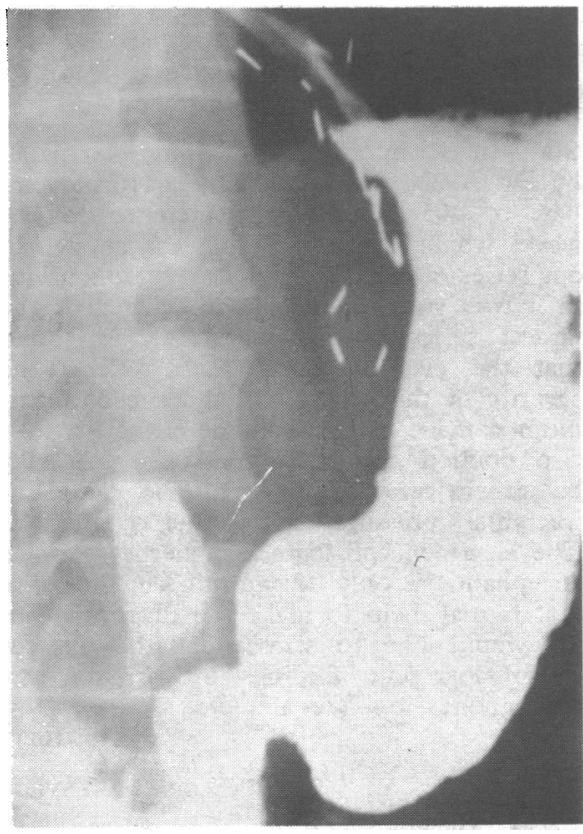

One year later he was unable to work for six weeks because of recurrence of pain similar to that for which his operation had been performed. He complained of poor appetite, epigastric fullness, and, again, flatulence. He had lost $5 \mathrm{~kg}$ in weight but was otherwise well. Acid tests were performed in the professorial surgical unit at the General Infirmary at Leeds and showed: resting juice $110 \mathrm{ml}$; spontaneous acid output nil; peak acid output (intravenous insulin) 0.90 $\mathrm{mEq} / \mathrm{hr}$ free acid; maximum acid output (pentagastrin) $7.77 \mathrm{mEq} / \mathrm{hr}$ total acid; and insulin test late positive. Dr. R. F. Ashwin (who had carried out barium-meal studies on this patient in 1966 and 1971) reported that there was a small lesser-curve gastric ulcer (see Fig) where the stomach had been normal before, whereas the pyloric channel and duodenal cap now filled normally.

Fortunately the patient has been able to return to work as his pain has gone. Although his flatulence has abated he still cannot eat more than half-sized meals and he has not yet regained his lost weight.
Highly selective vagotomy 12 is becoming increasingly popular as the operation of choice in cases of uncomplicated duodenal ulcer. There are cogent reasons for its popularity which do not need to be enumerated here. Latterly the operation has been extended to cases of benign gastric ulcer, ap parently with equal success ${ }^{3} 4$. This case has been reported because it is believed to be the first case of benign lesser-curve gastric ulcer caused by highly selective vagotomy No similar case has arisen in more than 300 highly selective vagotomies for duodenal ulcer in Copenhagen and Leeds 5 . It could easily be argued that this patient inadvertently underwent total gastric vagotomy without drainage $-a$ situation more akin to truncal vagotomy alone and liable to give rise to secondary gastric ulceration from stasis. Perhaps a $5.5 \mathrm{~cm}$ lesser-curve measurement for remaining antral innervation was too mean in this individual-certainly no other method was used to distinguish between antrum and fundus.

Highly selective vagotomy alone promises to be better than truncal vagotomy with drainage, but it is slightly more difficult Thus cases in which the vagotomy falls short of its aims may be expected. These should be recognized rather than condemning the aim of preserving an undrained innervated antrum.

York County Hospital,

ROBERT HALI

Amdrup, E., and Jensen, H. E., Gastroenterology, $1970,59,522$

Johnston, and Wilkinson, A. R., British Fournal of Surgery, 1970, 57, 289.

3 Johnston, D., Humphrey, C. S., Smith, R. B. and Wilkinson, A. R., British Fournal of Surgery, 1972, 59, 787 .

Burge, H., British Medical fournal, 1972, 4, 360 5 Johnston, D., personal communication 1972.

\section{AFIF-Related Protein and Precipitation} Reactions

SIR,-Caution must be exercised before interpretations of the mode of inheritance of von Willebrand's disease are made from the studies reported by Dr. L. Holmberg and Professor I. M. Nilsson ${ }^{1}$ (5 August, p. 317), as the authors do not report on the steps they undertook to ensure that their antiserum was truly specific. The antibody was prepared by injection of AHF purified by Sepharose $6 \mathrm{~B}$ chromatography into rabbits. It is well known that during the purification of AHF lipoproteins and IgM cannot be excluded from the purified AHF.2 To en sure that the antiserum is specific to "AHF related antigen" the antiserum should be absorbed with a plasma known to contain minimal amounts of AHF-related protein but which is otherwise normal.

We have produced antiserum to AHF by a method similar to that used by the authors. The serum had a high specific activity against AHF in a coagulation system and produced a single precipitin line against purified AHF and cryoprecipitate. It has been used by us to detect AHF-related protein by means of a coagulation system. When this antiserum was absorbed with the plasma of a patient with von Willebrand's disease with low AHF activity (1\%) and low AHFrelated protein anti-AHF activity persisted but the precipitation lines were lost. We concluded that the precipitation reaction was due to antibodies to proteins contaminating the purified AHF.
Using this antiserum and a coagulation system we have found AHF-related protein in 20 children with haemophilia and in normal adults. In eight patients with von Willebrand's disease we found that AHF activity and AHF-related protein were reduced. There was a strong correlation between AHP activity and AHF-related protein. We have not found any patients with von Willebrand's disease who have low ac tivity and normal AHF protein.

It would be of great interest to know whether the authors have used a coagulation system to test the levels of AHF-related protein in their patients and whether they were able to confirm the results of precipitation methods.-We are, etc.

HENRY Exart

HOLGER HELLIGEI ROBERT MUNTZ

Royal Children's Hospital Research Foundation, Victoria, Australia

1 Hershgold, E. J., Davison, A. M., and Janszen
M. E.; fourmal of Laboratory and Clinica
Medicine, 1971, 77, 185 .

\section{Trapped Nerves}

Sir,-In support of Mr. J. D. Sidey and Dr. M. D. Mehta (9 September, p. 647) I offer the experience gathered in the treatment of well over 1,000 non-impact craniocervical injuries with nerve entrapment symtomatology. Most of these cases were due to rear-end auto collisions and had treat ment for six weeks to six months, with resolution in $90 \%$ by 12 weeks if treatment was actively pursued. I found recognition of these painful lesions to be very poor in the medical community in general, and $20 \%$ of the cases were referred as a "last resort" when chronicity was established. Fortunately, conservative treatment is usually effective even in cases of several months duration. The other cases were acute.

Three main distributions of pain were defined: (l) Pain in the occipital region of the neck radiating to the vertex, temples, and behind the eyes. (2) Pain arising at the level of the transverse process of the fifth and/or sixth cervical vertebrae and radiating up the neck to the occiput and/or down to the point of the shoulder and/or along the medial border of the scapula. (3) Low back pain (with muscle spasm) radiating along the fifth lumbar and first sacral distribution. Neurological signs were present in $75 \%$ of cases, involving the triceps, ankle, and knee jerks (as depression of activity) in that order. Some of the other symptoms noted were changes in visual acuity $(90 \%$ in patients over 45) and alterations in libido of varying severity, from impotence in males to serious aversion in the female not related to the degree of pain involved. Horner's syndrome was seen in $1 \%$ of cases and emotional disturbances related to frontal and temporal lobe damage (aggressiveness and hostility mostly) in 2\%. Mydriasis was seen twice.

Diagnosis was established by injection of $2 \%$ lignocaine, which usually gave immediate relief of pain. This response was so dramatic that the 10 patients not responding were classed as having non-organic disease.

Treatment was by: (1) Injection of $2 \%$ or $1 \%$ alcohol in 3-5 ml $2 \%$ lignocaine with $2 \mathrm{ml}$ of Depo-Medrone (containing $80 \mathrm{mg}$ methylprednisolone acetate) in cases of six 